\title{
Work Absenteeism and Its Determinant Factors in Patients with Ankylosing Spondylitis: A Cross-Sectional Study
}

\author{
Julide ÖNCÜ, Fatma BAŞOĞLU, Banu KURAN \\ Department of Physical Medicine and Rehabilitation, Şişli Etfal Training and Research Hospital, İstanbul, Turkey
}

Objectives: This study aims to investigate work absenteeism and its determinant factors in patients with ankylosing spondylitis (AS).

Patients and methods: A total of 88 patients were referred to our outpatient clinic with a definitive diagnosis of AS. Of these, the 46 full-time workers ( 9 women; 37 men; mean age 38.7 \pm 8.5 years; range 16 to 60 years) were evaluated. The impact of disease-related factors on absenteeism were analyzed via the Bath Ankylosing Spondylitis Disease Activity Index (BASDAI), the Bath Ankylosing Spondylitis Function Index (BASFI), and the Ankylosing Spondylitis Quality of Life (ASQoL) questionnaire. The disease duration and morning stiffness as well as factors such as job-related physical duties [heavy lifting ( $>10 \mathrm{~kg}$ ), working with the trunk in an awkward posture, prolonged sitting and standing while working, driving a vehicle for $>6 \mathrm{hrs} /$ day], type of occupation, duration of work (years), average hours worked per week, and psychosocial risk factors (job-related distress, fear of returning to work, and job satisfaction) were also assessed.

Results: The mean disease duration was $8 \pm 7$ years, and the mean days of work absenteeism were $44.8 \pm 10.1$. There was a significant correlation between work absenteeism and the BASDAI, BASFI, ASQoL, and morning stiffness scores. Among the job-related physical duties and psychosocial risk factors, heavy lifting, job-related distress, fear of returning to work, and job satisfaction were associated with most days of absenteeism. In a stepwise logistic regression analysis, the only items that were significantly related to absenteeism were the high BASDAI scores and low job satisfaction. None of the other demographic characteristics or physical factors demonstrated significance.

Conclusion: Our study results showed that work absenteeism is an important outcome of AS, with the most important determinant factors being the BASDAI scores and the level of job satisfaction.

Keywords: Absenteeism; ankylosing spondylitis; job-related risk factors.

Ankylosing spondylitis (AS) is a chronic inflammatory disease of the joints and entheses. ${ }^{1}$ It usually starts in the third decade of life of the patients just as they are becoming more established in their careers, ${ }^{1}$ and can lead to significant physical limitations that affect their ability to work. ${ }^{2,3}$ Since AS starts at an early age and causes significant problems related to job retention and work absenteeism, the lifetime economic burden is high. ${ }^{4,5}$

Data from the United Kingdom suggests that 50\% of AS patients who are of a working age have lost their job due to disease activity. ${ }^{6}$ Of those who have a job, 50\% have moderate work instability or are at a high risk of losing their jobs. ${ }^{6}$ Furthermore, a report from the Netherlands determined that AS patients with a paying job lost $5.0 \%$ of the total number of work days in a year, which accounted for a mean of 10.1 days of sick leave per patient per year. ${ }^{7}$

While several studies have been published regarding rheumatoid arthritis (RA) and its relationship to work absenteeism and its determinants, very little data exists in cases involving AS, although it is a known cause of job retention and instability. ${ }^{8-13}$ Therefore, the aim of this study was to investigate work absenteeism and its associated risk factors, including job-related physical duties, as well as the psychosocial and disease-related factors in patients with AS who regularly visit our clinic.

Received: June 25, 2013 Accepted: October 21, 2013

Correspondence: Julide Öncü, M.D. Şişli Etfal Eğitim ve Araştırma Hastanesi Fizik Tedavi ve Rehabilitasyon Kliniği, 34360 Şişli, İstanbul, Turkey. Tel: +90 507 - 2316817 e-mail: julideoncu@yahoo.com 


\section{PATIENTS AND METHODS}

We performed a cross-sectional monocenter study with patients who were admitted to the physical medicine and rehabilitation clinic at the Istanbul Sisli Etfal Training and Research Hospital. A total of 88 patients with AS were seen in our clinic between years of 2011 and 2012, but only the 46 patients who had full-time paying jobs were included in the study. In addition, the study participants also had a confirmed diagnosis of AS according to the Assessment of Ankylosing Spondylitis (ASAS) criteria, spoke Turkish, and were willing to fill out a questionnaire. Those who were part-time workers $(n=16)$ and those who had retired due to health problems $(n=14)$ or were temporarily disabled and were receiving benefits $(n=12)$ were excluded from the study. Additionally, those patients scheduled to have orthopedic or neurosurgery and those with psychiatric disorders, an inadequate mental state, or other systemic diseases (i.e.. cardiovascular, respiratory, gastrointestinal, renal, or metabolic) were also not included. The study design, protocols, and procedures were approved by the hospital medical ethics committee, and after explaining the study objectives, written informed consent was obtained from each participant.

The patients' demographics (age, gender, marital status, educational level) were noted, and the causes of work absenteeism were analyzed, with particular attention paid to disease activity and jobrelated characteristics as well as the ergonomic and psychosocial risk factors. The measures of disease activity were evaluated by the Bath Ankylosing Spondylitis Disease Activity Index (BASDAI), ${ }^{14}$ the Bath Ankylosing Spondylitis Functional Index (BASFI) ${ }^{15}$ disease duration (years), and morning stiffness (minutes). Furthermore, the patients' disease-related quality of life (QoL) was evaluated by the Ankylosing Spondylitis Quality of Life (ASQoL) questionnaire, a disease-specific, needs-based instrument in which higher scores indicate more active or severe AS. ${ }^{16}$

The details about the participants' occupational history were also recorded, including the type of work [(manual workers were defined as artisans, shopkeepers, and working class patients and sedentary workers as managers and salaried employees working in finance and business administration), drivers (transport and operators), liberal arts professionals, and intellectual professionals (e.g., teachers and lawyers)], degree of job-related physical activity (driving vehicles at least six hours per day, working with the trunk in an awkward position (i.e., a bent or twisted back), sitting and standing for long periods, lifting heavy weights $(<10 \mathrm{~kg})$, duration of work (years), average hours of work per week, and absences due to sickness.

Additionally, each patient filled out a questionnaire comprised of questions related to psychosocial risk factors. Some of the questions were partly based on the instrument proposed by Linton and Boersma ${ }^{17}$ while others were specially designed for this study. The questions mainly focused on three areas: (i) jobrelated distress ("How much have you been bothered by feeling depressed, tense, or anxious in the past week?"), (ii) fear of returning to work ("In your estimation, what are the chances that you will be working in six months?"), and (iii) job satisfaction ("If you take into consideration your work routine, management, salary, promotion possibilities, and colleagues, how satisfied are you with your job?", according to visual analog scale between 0-100 cm). After examining all of the data, we then determined the amount of long-term absenteeism $(>30$ days per year) for each of the participants for the period of 12-month.

All analyses were carried out using the SPSS 10.1 for Windows (SPSS Inc., Chicago, IL, USA) software program, and a $p$ value of $<0.05$ was considered to be statistically significant. The continuous variables were presented as mean \pm standard deviation (SD), and the categorical variables were given as frequencies and percentages. We dichotomized the participants into two groups, with category I containing the patients with short-term absenteeism ( $<30$ days per year), and category II having those with long-term absenteeism (>30 days per year). Before analyzing our data statistically, the normality was determined via a one-sample KolmogorovSmirnov test. However, this test proved not to be normal for our data $(z=0.398 ; p=0.041$ for category I and $p<0.05$ for category II), so we compared these two groups using the Wilcoxon signed-rank test. A series of stepwise regression analyses were also conducted to predict work absence as an outcome using job-related or disease-related characteristics as predictors, and a model was created which took into account whether the correlation analysis showed an individual or a combined correlation 


\begin{tabular}{|c|c|c|c|c|}
\hline & $\mathrm{n}$ & Mean \pm SD & Median & Min.-Max. \\
\hline Age (years) & & $38.7 \pm 8.5$ & & \\
\hline \multicolumn{5}{|l|}{ Gender } \\
\hline Female & 20 & & & \\
\hline \multicolumn{5}{|l|}{ Marital status } \\
\hline Married & 87 & & & \\
\hline \multicolumn{5}{|l|}{ Educational level } \\
\hline Primary school & 75 & & & \\
\hline High school & 14 & & & \\
\hline University graduate & 11 & & & \\
\hline Duration of arthritis (years) & & $8.4 \pm 7.3$ & & \\
\hline BASDAI score & & $6.0 \pm 1.2$ & 5.1 & $1.0-7.2$ \\
\hline BASFI score & & $3.5 \pm 1.2$ & 2.9 & $1.0-4.9$ \\
\hline ASQoL score & & $6.7 \pm 3.8$ & 7.5 & $1.0-18$ \\
\hline Morning stiffness (minutes) & & $45.5 \pm 15.7$ & & \\
\hline \multicolumn{5}{|l|}{ Pain sites } \\
\hline Neck & 10 & & & \\
\hline Upper back & 42 & & & \\
\hline Lower back & 48 & & & \\
\hline Shoulders & 0 & & & \\
\hline Legs & 0 & & & \\
\hline
\end{tabular}

via Cox \& Snell's R-square model $\left(\mathrm{R}^{2}=0.307\right.$; chisquare $=13.197 ; \mathrm{p}=0.001$ ).

\section{RESULTS}

The demographic and clinical variables of the patients are presented in Table 1, and all had the predominant axial form of AS.

The unemployment rate was $30 \%$, with $16 \%$ $(\mathrm{n}=14)$ having retired for health reasons and $14 \%$ $(n=12)$ being temporarily disabled (receiving a benefit allowance). In addition, $75.4 \%$ were manual workers [working class (49.2\%), shopkeepers (19\%), and artisans (7.2\%)], whereas $24.6 \%$ were sedentary workers [managers and salaried employees in the business, finance, or administration fields (5\%), drivers (transport, equipment operators) (9.6\%), intellectual professionals (teachers and lawyers) (3\%), and liberal arts professionals (7\%)]. Furthermore, we determined that the mean number of sick leave days was $44.8 \pm 10.1$. Other details related to their jobs are presented in Table 2 .

Regarding the job-related physical risk factors, $31 \%(n=12)$ drove vehicles more than six hours a day, 30\% ( $\mathrm{n}=13)$ had to do heavy lifting $(10-25 \mathrm{~kg})$, $25 \%(n=11)$ worked with their trunks in an awkward position, and $23 \%(\mathrm{n}=10)$ worked for prolonged periods in a sitting or standing posture. Moreover, the mean level of distress related to work was
$32.0 \pm 12.1 \mathrm{~cm}$, whereas it was $40.1 \pm 10.2 \mathrm{~cm}$ for fear of returning to work and $58.6 \pm 25.0 \mathrm{~cm}$ for job satisfaction (Table 3).

The results of the correlation analysis are shown in Table 4, and we found that the relationship between work absenteeism and the BASDAI $(\mathrm{r}=0.53$; $\mathrm{p}<0.01)$ and the BASDAI combined with the level of job satisfaction $(r=-0,460 ; p<0.01)$ were highly significant. In addition, the relationships between absenteeism and the ASQoL $(r=-0.33 ; \mathrm{p}<0.05)$,

Table 2. Employment characteristics of the study participants

\begin{tabular}{lcc}
\hline Current work status & $\mathrm{n}$ & Mean $\pm \mathrm{SD}$ \\
\hline Full time employment & 46 & \\
Average hours worked per week & & $48.3 \pm 7.5$ \\
Duration of work (years) & & $8.4 \pm 7.3$ \\
Occupational type & 75.4 & \\
Manual & 49.1 & \\
$\quad$ Workingclass & 19.1 & \\
Shopkeepers & 7.2 & \\
Artisans & 24.6 & \\
Sedentary & 5 & \\
$\quad$ Business, finance, administration & 9.6 & \\
Transport, equipment operators & 7 & \\
Liberal professionals & 3 & \\
Intellectual professionals & & \\
Number of patients per days of sick leave & 56 & \\
0-30 days & 35 \\
31-60 days & 19 & \\
61-180 days & 0 & \\
91-180 days & & \\
Mean days of sick leave (over 12 months) & & \\
\hline SD: Standard deviation. & &
\end{tabular}




\begin{tabular}{|lcccc|}
\hline \multicolumn{4}{l}{ Table 3. Job-related physical and psychosocial risk factors of the study participants } \\
\hline & $n$ & Mean \pm SD & Median & Min.-Max. \\
\hline Physical factors & 30 & & & \\
$\quad$ Heavy lifting (10-25 kg) & 25 & & & \\
$\quad$ Working with the trunk in an awkward position & 23 & & & \\
$\quad$ Prolonged sitting and standing & 31 & $32.0 \pm 12.1$ & 40 & $0-100$ \\
$\quad$ Driving vehicles more than six hours a day & & $40.1 \pm 10.2$ & 48 & $0-100$ \\
Work-related distress $(0-100 \mathrm{~cm})$ & & $58.6 \pm 25.0$ & 44 & $0-100$ \\
Fear of returning to work (0-100 cm) & & & \\
Job satisfaction (0-100 cm) & & & \\
SD: Standard deviation; Min.: Minimum; Max.: Maximum.
\end{tabular}

morning stiffness $(\mathrm{r}=0.32 ; \mathrm{p}<0.05)$, the BASFI $(r=0.34 ; p<0.05)$, heavy lifting $(r=0.32 ; p<0.05)$, fear of returning to work $(\mathrm{r}=0.34 ; \mathrm{p}<0.05)$, and workrelated distress $(r=0.34 ; p<0.05)$ were moderately significant.

We also determined that the mean amount of sick leave was $44.88 \pm 5.1$ days. In addition, when the category I and category II were compared (Table 5), the BASDAI scores $(p<0.01)$, level of job satisfaction $(p<0.01)$, the BASFI scores $(p<0.05)$, and the scores on the ASQoL questionnaire $(p<0.05)$ were significantly lower in the patients in category II.

Because the outcomes were divided according to these two categories, stepwise logistic regression was used to analyze the predictive ability of the all factors (Table 6), and the only factors which predicted sick leave were job satisfaction $(p<0.01)$ and the BASDAI $(p<0.01)$. An increase of 1 point on the BASDAI would increase the chances of being in category II by 3.5-fold while the same increase in combination with job satisfaction would cause an increase of 1.13 fold (1/0.88) of being in

Table 4. Correlation analysis between absenteeism and clinical parameters

\begin{tabular}{lcc}
\hline & $\begin{array}{c}\text { Correlation } \\
\text { coefficients* }\end{array}$ & $p$ \\
\hline Work absenteeism (days) & 0.532 & 0.001 \\
$\quad$ BASDAI score & 0.340 & 0.039 \\
BASFI score & -0.460 & 0.005 \\
Job satisfaction (0-100 cm) & 0.329 & 0.041 \\
Morning stiffness (min) & -0.336 & 0.047 \\
ASQoL score & 0.325 & 0.049 \\
Heavy lifting & 0.341 & 0.045 \\
Fear of returning to work & 0.345 & 0.043 \\
Work-related distress & & \\
\hline * Pearson correlational analysis used for parametric data and Spearman analysis used for \\
Likert-type data; BASDAI: Bath Ankylosing Spondylitis Disease Activity Index; BASFI: \\
$\begin{array}{l}\text { Bath Ankylosing Spondylitis Functional Index; ASQoL: Ankylosing Spondylitis Quality } \\
\text { of Life questionnaire. }\end{array}$
\end{tabular}

category I (Table 6). Other than job satisfaction, no demographic characteristics, occupational type, job-related physical factors, or psychosocial risk factors proved to be significant determinants of long-term absenteeism.

\section{DISCUSSION}

Our study revealed that $52 \%(n=46)$ of our patients with full-time employment were under the risk of long-term absenteeism, and the major determinants were the BASDAI and job satisfaction, regardless of the type of work. To our knowledge, this is the first study that has assessed the employment status and sought to determine the causes of work absenteeism by examining disease activity scores and job-related physical and psychosocial risk factors.

With regard to the number of days of sick leave for the patients with a paying job, our findings were similar to those of other studies as we determined that there were 44.8 days of sick leave per patient per year. Similarly, Urbánek et al. ${ }^{18}$ reported 39.5 days of disease-specific sick leave per patient per year in a study in the Czech Republic, and Ramos-Remus et al. ${ }^{19}$ in a cross-sectional study from Mexico determined that there were 45.8 days of sick leave per year. However, in a prospective study, the same authors found that only one day of sick leave per patient per month could be attributed to disease.$^{20}$ Although our findings were similar, it should be noted that because our study was crosssectional in nature and not a follow-up study of an inception cohort, an overestimation of the mean number of sick leave days might have occurred. The most important reason for work absenteeism reported in other studies was that AS- attributable sick leave might not be related to only $\mathrm{AS}^{19,20}$ because it is not clear whether these patients can 
Table 5. The differences between category I (absent <30 days/year) and category II (absent $>30$ days/year)

\begin{tabular}{lccccr}
\hline & \multicolumn{2}{c}{ Category I } & & \multicolumn{2}{c}{ Category II } \\
\cline { 2 - 3 } & Median & Min.-Max. & Median & Min.-Max. & $p$ \\
\hline BASDAI & 2.6 & $1.0-4.5$ & 5.8 & $3.6-7.8$ & 0.001 \\
Job satisfaction & 8.5 & $4.2-9.9$ & 2.7 & $2.0-3.7$ & 0.004 \\
BASFI & 2.6 & $2.0-2.9$ & 4.3 & $3.0-5.0$ & 0.046 \\
ASQoL & 6.5 & $2.5 ; 9.7$ & 9.4 & $4.8-13.0$ & 0.045 \\
\hline Min.: Minimum; Max.: Maximum; BASDAI: Bath Ankylosing Spondylitis Disease Activity & Index; BASFI: Bath Ankylosing Spondylitis Functional Index; \\
ASQoL: Ankylosing Spondylitis Quality of Life Questonnaire. & & & \\
\hline
\end{tabular}

Table 6. The results of a stepwise logistic regression analysis

\begin{tabular}{lccccccc}
\hline & B & SE & Wald & df & Sig & Exp(B) & $95 \%$ CI \\
\hline BASDAI & 1.274 & 0.453 & 7.896 & 1 & 0.005 & 3.575 & $3.02-3.91$ \\
BASDAI + job satisfaction & -0.124 & 0.061 & 4.113 & 1 & 0.043 & 0.884 & $0.082-.094$ \\
\hline BASDAI: Bath Ankylosing Spondylitis Disease Activity Index; Cl: Confidence interval. & & & & & \\
\hline
\end{tabular}

really distinguish between illness due to AS and other causes. This is especially true for manual workers because they can also suffer from several chronic musculoskeletal disorders; hence, the amount of sick leave may be somewhat exaggerated. Furthermore, the proportion of manual workers $(75 \%)$ versus sedentary workers $(25 \%)$ was higher in our study, but we found no relationship between absenteeism and type of occupation. Moreover, none of the physical job-related factors, except for heavy lifting, had any correlation with work-related absenteeism. Therefore, we believe that the absenteeism in our study participants might be attributable to AS in our study, and this hypothesis is further supported by the results of our stepwise regression analysis which showed that the BASDAI and job satisfaction were the only causes of work-related absenteeism. Although we are somewhat reluctant to accept the relative proportions of disease-specific and non-specific sick leave presented here, it is clear that work-related absenteeism for patients with AS cannot be explained solely by the heavy lifting associated with manual work.

Early identification of those having a risk of long-term absenteeism by means of psychosocial prognostic factors has been increasingly advocated by investigators. ${ }^{21}$ These include components such as the attitudes and beliefs of the patient (fear of returning to work), emotional problems at work (job-related distress), and job satisfaction. ${ }^{21}$ These constructs, known as "yellow-flags", have also been identified as a primary determinant of pain and disability and are associated with longer periods of missed work. ${ }^{21}$ To date, however, reports about psychosocial prognostic factors have only been available for patients with musculoskeletal pain problems and not for those with AS. ${ }^{22-26}$ Since there is no instrument currently available to measure these prognostic factors in AS, the only way to identify clients who are at risk for long-term absenteeism is through a comprehensive self-report assessment that includes ergonomic and psychosocial risk factors. Since most of the factors included in this instrument were somewhat related to absenteeism associated with AS, these should be considered when attempting to identify patients at high risk for longterm absenteeism in clinical practice.

Among the clinical parameters that we used, the BASDAI was the strongest factor related to absenteeism, although there were somewhat weak correlations with morning stiffness, disease duration, and the BASFI. The association between the amount of sick leave and disease activity (the BASDAI, morning stiffness) or function (the BASFI) might indicate that our patients had higher disease activity; thus, those with early or mild disease severity were not included in our study. This could be considered by some to be a limitation of our study.

The most striking feature of our study was the presence of a significant correlation between absenteeism and the BASDAI and job satisfaction, and this relationship was strong enough to have a better predictive power for long-term absenteeism than the other risk factors in our study. Since there were multiple mechanisms that caused the increased amount of sick leave, including disease-related, work-related, 
sociodemographic, and psychosocial factors, ${ }^{27}$ all of them should be considered when trying to predict which patients are at risk for long-term absenteeism.

Our study also provided additional information related to work status, especially since this topic has not been previously studied in Turkey. Similar to our findings, according to a study by Boonen et al., ${ }^{28}$ work disability associated with AS in European countries was higher than expected. In addition, the same authors found that the risk for withdrawal from work in the Netherlands was about three times higher in patients with AS than for the general population. ${ }^{29}$

Although, we examined the occupations of our patients in detail, our data indicated that the type of job played no role in absenteeism. Furthermore, we found no differences regarding the type of occupation in categories I and II. This might be due to the fact that our patients' occupations did not show a balanced distribution since the majority did manual work. For the same reason, we could not find any connection between work-related absenteeism and physical factors. Therefore, prospective studies with a larger number of patients working in various areas of industry should be conducted including the factors that may influence work absenteeism for patients with AS.

\section{Conclusion}

The results of our study showed that the main determinants of work absenteeism in patients with AS were the BASDAI and the BASDAI combined with job satisfaction rather than any demographic or workrelated physical characteristics. On an individual level, because persistent inflammatory musculoskeletal pain significantly disrupts a variety of functions and affects the patient's QoL, early identification and intervention for those at risk for long-term absenteeism would greatly reduce costs and limit personal suffering. Although we believe that our findings were significant, further prospective studies are needed to evaluate our conclusions and verify our data.

\section{Declaration of conflicting interests}

The authors declared no conflicts of interest with respect to the authorship and/or publication of this article.

\section{Funding}

The authors received no financial support for the research and/or authorship of this article.

\section{REFERENCES}

1. van der Linden SM, Valkenburg HA, de Jongh BM, Cats A. The risk of developing ankylosing spondylitis in HLAB27 positive individuals. A comparison of relatives of spondylitis patients with the general population. Arthritis Rheum 1984;27:241-9.

2. Cakar E, Taskaynatan MA, Dincer U, Kiralp MZ, Durmus O, Ozgül A. Work disability in ankylosing spondylitis: differences among working and work-disabled patients. Clin Rheumatol 2009;28:1309-14.

3. Ariza-Ariza R, Hernández-Cruz B, Collantes E, Batlle E, Fernández-Sueiro JL, Gratacós J, et al. Work disability in patients with ankylosing spondylitis. J Rheumatol 2009;36:2512-6.

4. Boonen A, van der Heijde D, Landewé R, Guillemin F, Spoorenberg A, Schouten $\mathrm{H}$, et al. Costs of ankylosing spondylitis in three European countries: the patient's perspective. Ann Rheum Dis 2003;62:741-7.

5. Boonen A, van der Linden SM. The burden of ankylosing spondylitis. J Rheumatol Suppl 2006;78:4-11.

6. Barkham N, Kong KO, Tennant A, Fraser A, Hensor E, Keenan AM, Emery P. The unmet need for antitumour necrosis factor (anti-TNF) therapy in ankylosing spondylitis. Rheumatology (Oxford) 2005;44:1277-81.

7. Boonen A, Chorus A, Miedema H, van der Heijde D, van der Tempel $\mathrm{H}$, van der Linden S. Employment, work disability, and work days lost in patients with ankylosing spondylitis: a cross sectional study of Dutch patients. Ann Rheum Dis 2001;60:353-8.

8. Yelin E, Meenan R, Nevitt M, Epstein W. Work disability in rheumatoid arthritis: effects of disease, social, and work factors. Ann Intern Med 1980;93:551-6.

9. Reisine ST, Grady KE, Goodenow C, Fifield J. Work disability among women with rheumatoid arthritis. The relative importance of disease, social, work, and family factors. Arthritis Rheum 1989;32:538-43.

10. Pincus T, Callahan LF, Sale WG, Brooks AL, Payne LE, Vaughn WK. Severe functional declines, work disability, and increased mortality in seventy-five rheumatoid arthritis patients studied over nine years. Arthritis Rheum 1984;27:864-72.

11. Reisine S, McQuillan J, Fifield J. Predictors of work disability in rheumatoid arthritis patients. A five-year followup. Arthritis Rheum 1995;38:1630-7.

12. Callahan LF, Bloch DA, Pincus T. Identification of work disability in rheumatoid arthritis: physical, radiographic and laboratory variables do not add explanatory power to demographic and functional variables. J Clin Epidemiol 1992;45:127-38.

13. Fifield J, Reisine ST, Grady K. Work disability and the experience of pain and depression in rheumatoid arthritis. Soc Sci Med 1991;33:579-85.

14. Garrett S, Jenkinson T, Kennedy LG, Whitelock H, Gaisford P, Calin A. A new approach to defining disease status in ankylosing spondylitis: the Bath Ankylosing Spondylitis Disease Activity Index. J Rheumatol 1994;21:2286-91. 
15. Calin A, Garrett S, Whitelock H, Kennedy LG, O'Hea J, Mallorie $\mathrm{P}$, et al. A new approach to defining functional ability in ankylosing spondylitis: the development of the Bath Ankylosing Spondylitis Functional Index. J Rheumatol 1994;21:2281-5.

16. Doward LC, Spoorenberg A, Cook SA, Whalley D, Helliwell PS, Kay LJ, et al. Development of the ASQoL: a quality of life instrument specific to ankylosing spondylitis. Ann Rheum Dis 2003;62:20-6.

17. Linton SJ, Boersma K. Early identification of patients at risk of developing a persistent back problem: the predictive validity of the Orebro Musculoskeletal Pain Questionnaire. Clin J Pain 2003;19:80-6.

18. Urbánek T, Sitajová H, Hudáková G. Problems of rheumatoid arthritis and ankylosing spondylitis patients in their labor and life environments. Czech Med 1984;7:78-89.

19. Ramos-Remus C, Macias MA, Suarez-Almazor ME, PrietoRE, Gutierrez-Urena S. Labor status and workingdays lost in a consecutive sample of 103 patients with ankylosing spondylitis (AS). Arthritis Rheum Suppl 1997:1392.

20. Ramos-Remus C, Prieto-Parra RE, Michel-Diaz J, Gutierrez-Urena S, Suarez-Almazor ME. A five-year cumulative analysis of labor-status and lost working days in patients with ankylosing spondylitis (AS). Arthritis Rheum Suppl 1998:1136.

21. Westman A, Linton SJ, Ohrvik J, Wahlén P, Leppert J. Do psychosocial factors predict disability and health at a 3-year follow-up for patients with nonacute musculoskeletal pain? A validation of the Orebro Musculoskeletal Pain Screening Questionnaire. Eur J Pain 2008;12:641-9.
22. Dunstan DA, Covic T, Tyson GA, Lennie IG. Does the Orebro Musculoskeletal Pain Questionnaire predict outcomes following a work-related compensable injury? Int J Rehabil Res 2005;28:369-70.

23. Hurley DA, Dusoir TE, McDonough SM, Moore AP, Linton SJ, Baxter GD. Biopsychosocial screening questionnaire for patients with low back pain: preliminary report of utility in physiotherapy practice in Northern Ireland. Clin J Pain 2000;16:214-28.

24. Grotle M, Vøllestad NK, Brox JI. Screening for yellow flags in first-time acute low back pain: reliability and validity of a Norwegian version of the Acute Low Back Pain Screening Questionnaire. Clin J Pain 2006;22:458-67.

25. Andersen LL, Clausen T, Persson R, Holtermann A. Perceived physical exertion during healthcare work and prognosis for recovery from long-term pain in different body regions: Prospective cohort study. BMC Musculoskelet Disord 2012;13:253.

26. Stewart SK, Rothmore PR, Doda DV, Hiller JE, Mahmood MA, Pisaniello DL. Musculoskeletal pain and discomfort and associated worker and organizational factors: A cross-sectional study. Work 2013. [Epub ahead of print]

27. Ward MM, Kuzis S. Risk factors for work disability in patients with ankylosing spondylitis. J Rheumatol 2001;28:315-21.

28. Boonen A, Chorus A, Miedema $\mathrm{H}$, van der Heijde D, Landewé $\mathrm{R}$, Schouten $\mathrm{H}$, et al. Withdrawal from labour force due to work disability in patients with ankylosing spondylitis. Ann Rheum Dis 2001;60:1033-9.

29. Boonen A, van der Heijde D, Landewé R, Spoorenberg A, Schouten H, Rutten-van Mölken M, et al. Work status and productivity costs due to ankylosing spondylitis: comparison of three European countries. Ann Rheum Dis 2002;61:429-37. 